\title{
Production of medium-chain-length polyhydroxyalkanoates by sequential feeding of xylose and octanoic acid in engineered Pseudomonas putida KT2440
}

\author{
Sylvaine Le Meur ${ }^{1}$, Manfred Zinn ${ }^{1,2}$, Thomas Egli ${ }^{3}$, Linda Thöny-Meyer ${ }^{1}$ and Qun Ren ${ }^{1 *}$
}

\begin{abstract}
Background: Pseudomonas putida KT2440 is able to synthesize large amounts of medium-chain-length polyhydroxyalkanoates (mcl-PHAs). To reduce the substrate cost, which represents nearly $50 \%$ of the total PHA production cost, xylose, a hemicellulose derivate, was tested as the growth carbon source in an engineered P. putida KT2440 strain.
\end{abstract}

Results: The genes encoding xylose isomerase (Xy|A) and xylulokinase (Xy|B) from Escherichia coli W3110 were introduced into P. putida KT2440. The recombinant KT2440 exhibited a XylA activity of $1.47 \mathrm{U}$ and a XylB activity of $0.97 \mathrm{U}$ when grown on a defined medium supplemented with xylose. The cells reached a maximum specific growth rate of $0.24 \mathrm{~h}^{-1}$ and a final cell dry weight (CDW) of $2.5 \mathrm{~g} \mathrm{~L}^{-1}$ with a maximal yield of $0.5 \mathrm{~g} \mathrm{CDW} \mathrm{g}^{-1}$ xylose. Since no mcl-PHA was accumulated from xylose, mcl-PHA production can be controlled by the addition of fatty acids leading to tailor-made PHA compositions. Sequential feeding strategy was applied using xylose as the growth substrate and octanoic acid as the precursor for mcl-PHA production. In this way, up to $20 \% \mathrm{w} \mathrm{w}^{-1}$ of mcl-PHA was obtained. A yield of $0.37 \mathrm{~g}$ mcl-PHA per $\mathrm{g}$ octanoic acid was achieved under the employed conditions.

Conclusions: Sequential feeding of relatively cheap carbohydrates and expensive fatty acids is a practical way to achieve more cost-effective mcl-PHA production. This study is the first reported attempt to produce mcl-PHA by using xylose as the growth substrate. Further process optimizations to achieve higher cell density and higher productivity of mcl-PHA should be investigated. These scientific exercises will undoubtedly contribute to the economic feasibility of mcl-PHA production from renewable feedstock.

Keywords: mcl-PHA, Xylose, Octanoic acid, Pseudomonas putida KT2440, Sequential-feeding, Tailor-made PHA

\section{Background}

Polyhydroxyalkanoates (PHAs) are bacterial storage compounds produced widely by many microorganisms under nutrient limited growth conditions such as a nitrogen, phosphorous or oxygen starvation and when an excess of carbon source is present $[1,2]$. PHAs gained particular interest because they were shown to be biodegradable and biocompatible (see review [3]). Based on

\footnotetext{
* Correspondence: qun.ren@empa.ch

${ }^{1}$ Laboratory for Biomaterials, Swiss Federal Laboratories for Materials Science and Technology (Empa), Lerchenfeldstrasse 5, St. Gallen CH-9014, Switzerland Full list of author information is available at the end of the article
}

the chain length of the fatty acid monomers, PHAs can be classified into three categories: short-chain-length (scl) PHAs with 3 to 5 carbon atoms, medium-chainlength (mcl) PHAs with 6 to 14 carbon atoms and longchain-length (lcl) PHAs with more than 14 carbon atoms [4]. The difference in length and/or chemical structure of the alkyl side chain of the PHAs influences the material properties of the polymers to a great extent. The production of tailor-made mcl-PHAs enables to obtain the desired material properties using the appropriate fatty acid precursor. PHAs have been considered as an attractive ecofriendly alternative to petrochemical polymers. However, the much higher production cost 
compared with conventional petrochemical derived polymers has limited their widespread use.

Much effort has been devoted to reduce the price of PHAs by developing better bacterial strains, more efficient fermentation and/or more economical recovery processes [6-11]. It has been shown that the cost of raw materials (mainly the carbon source) contributes most significantly to the overall production cost of PHAs (up to $50 \%$ of the total production cost) [12]. The use of two kinds of carbon sources can be an attractive approach to reduce cost: the first carbon substrate is used for cell growth to obtain biomass, while the second one (which may be more expensive) allows the synthesis of PHA. The substrate for bacterial growth should be inexpensive and abundant. Xylose is second only to glucose in natural abundance [13]. Thus, it is a promising candidate substrate for bacterial growth.

D-Xylose is the dominant building unit of the hemicelluloses in plants of all species of the Gramineae. Hemicellulose, the third most abundant polymer in nature, can be easily hydrolyzed into fermentable sugars by either chemical or enzymatic hydrolysis [14]. In some plants, xylan comprises up to $40 \%$ of the total dry material. Annually, 60 billion tons of hemicelluloses are produced and remain almost completely unused [15]. It has been reported that the hemicellulose hydrolysate including xylose can be used by Candida blankii for efficient protein production [16]. There are also reports that poly (3-hydroxybutyrate) (PHB) could be synthesized from xylose in Pseudomonas pseudoflava and P. cepacia up to $22 \%\left(\mathrm{w} \mathrm{w}^{-1}\right)$ and $50 \%\left(\mathrm{w} \mathrm{w}^{-1}\right)$, respectively [17-19]. Furthermore, Escherichia coli harboring PHA synthesis genes of Ralstonia eutropha was reported to be able to accumulate PHB from xylose up to $74 \% \mathrm{w} \mathrm{w}^{-1}$ with a yield of $0.226 \mathrm{~g}$ PHB per g xylose [20].

Up to now, no report has been published on the production of mcl-PHA by using xylose. Since mcl-PHAs offer different material properties compared to sclPHAs, it would be interesting to investigate whether mcl-PHAs can be obtained from xylose. Pseudomonas putida KT2440, whose genome sequence is available (www.ncbi.nlm.nih.gov), is one of the best-characterized pseudomonads for mcl-PHA production [21]. It is able to synthesize and accumulate large amounts (up to $75 \% \mathrm{w} \mathrm{w}^{-1}$ ) of mcl-PHAs [22], but can only ferment a narrow range of sugars, in which xylose is not included. It has been shown that an engineered strain of $P$. putida S12 can utilize D-xylose and L-arabinose [23]. Introducing $x y l A$ (encoding xylose isomerase) and $x y l B$ (encoding xylulokinase) from $E$. coli into $P$. putida $\mathrm{S} 12$ enabled the latter to utilize xylose as the sole carbon source.

In this study, the possibility of using xylose as a growth carbon source and octanoic acid as mcl-PHA precusor in the controlled production of mcl-PHA by recombinant $P$. putida KT2440 was examined. The $x y l A B$ genes from $E$. coli W3110 were cloned into P. putida KT2440 and the obtained recombinant was studied for its ability to grow on xylose. For mcl-PHA production a sequential feeding strategy of using xylose and fatty acids was applied.

\section{Results}

\section{Cloning and expression of the $x y / A$ and $x y / B$ genes encoding xylose isomerase and xylulokinase}

To clone the $x y l A B$ genes, which are organized in an operon, of E. coli W3110, DNA primers PFXylA1 and PRXylB were designed based on the genomic sequence of $E$. coli W3110 (www.ncbi.nlm.nih.gov). These primers were used to amplify the $x y l A B$ fragment by PCR with W3110 chromosomal DNA as the template, leading to a $2.85 \mathrm{~kb}$ DNA product $(x y l A B)$. The PCR product was inserted into the shuttle vector pVLT33 as described in Methods, resulting in pSLM1 plasmid. P. putida KT2440 (pSLM1) was grown on E2 minimal medium with either $10 \mathrm{~g} \mathrm{~L}^{-1}$ xylose or glucose, leading to a $\mathrm{C} / \mathrm{N}$ ratio of $17 \mathrm{~g} \mathrm{~g}^{-1}$. P. putida KT2440 (pVLT33) was used as a control.

When grown on glucose, KT2440 (pVLT33) exhibited a higher maximal specific growth rate $\left(0.32 \mathrm{~h}^{-1}\right)$ than KT2440 (pSLM1) $\left(0.26 \mathrm{~h}^{-1}\right)$ (Figure 1A \& 1B). Due to nitrogen limitation both KT2440 (pVLT33) and KT2440 (pSLM1) exhibited reduced growth rate after $14 \mathrm{~h}$, with the latter having a dramatic reduction (Figure 1B). The difference in the degree of the reduction in growth rate could be partially caused by the different PHA content in KT2440 (pVLT33) (about 20\% $\mathrm{w} \mathrm{w}^{-1}$ ) and KT2440 (pSLM1) (about $1 \% \mathrm{w} \mathrm{w}^{-1}$ ). The different PHA content was also reflexed by the different maximum $\mathrm{OD}_{600}$ values reached by KT2440 (pVLT33) (4.28) and KT2440 (pSLM1) (2.94) (Figure 1A \& 1B). When xylose was used as the sole carbon source, KT2440 (pVLT33) was not able to grow during the entire test period (Figure 1C), whereas the recombinant KT2440 (pSLM1) exhibited a typical bacterial growth curve (Figure 1D\&1E). The maximum specific growth rate of the IPTG-induced recombinant KT2440 (pSLM1) culture was similar to the culture without induction, of $\mu=0.23 \mathrm{~h}^{-1}$ and $\mu=0.21 \mathrm{~h}^{-1}$, respectively. This demonstrates that the expression of $x y l A B$ from pSLM1 is not tightly regulated and $x y l A B$ can be expressed even without the induction by IPTG. The recombinant KT2440 (pSLM1) reached a maximal $\mathrm{OD}_{600}$ value of 3.66 on xylose. In all experiments the carbon substrate (either glucose or xylose) was not totally consumed at the end of the cultivation, around $4 \mathrm{~g} \mathrm{~L}^{-1}$ was left over in the culture broth.

These results suggest that the cloned $x y l A B$ from E. coli are functionally expressed in P. putida KT2440, and $x y l A B$ alone are sufficient to allow the growth of 

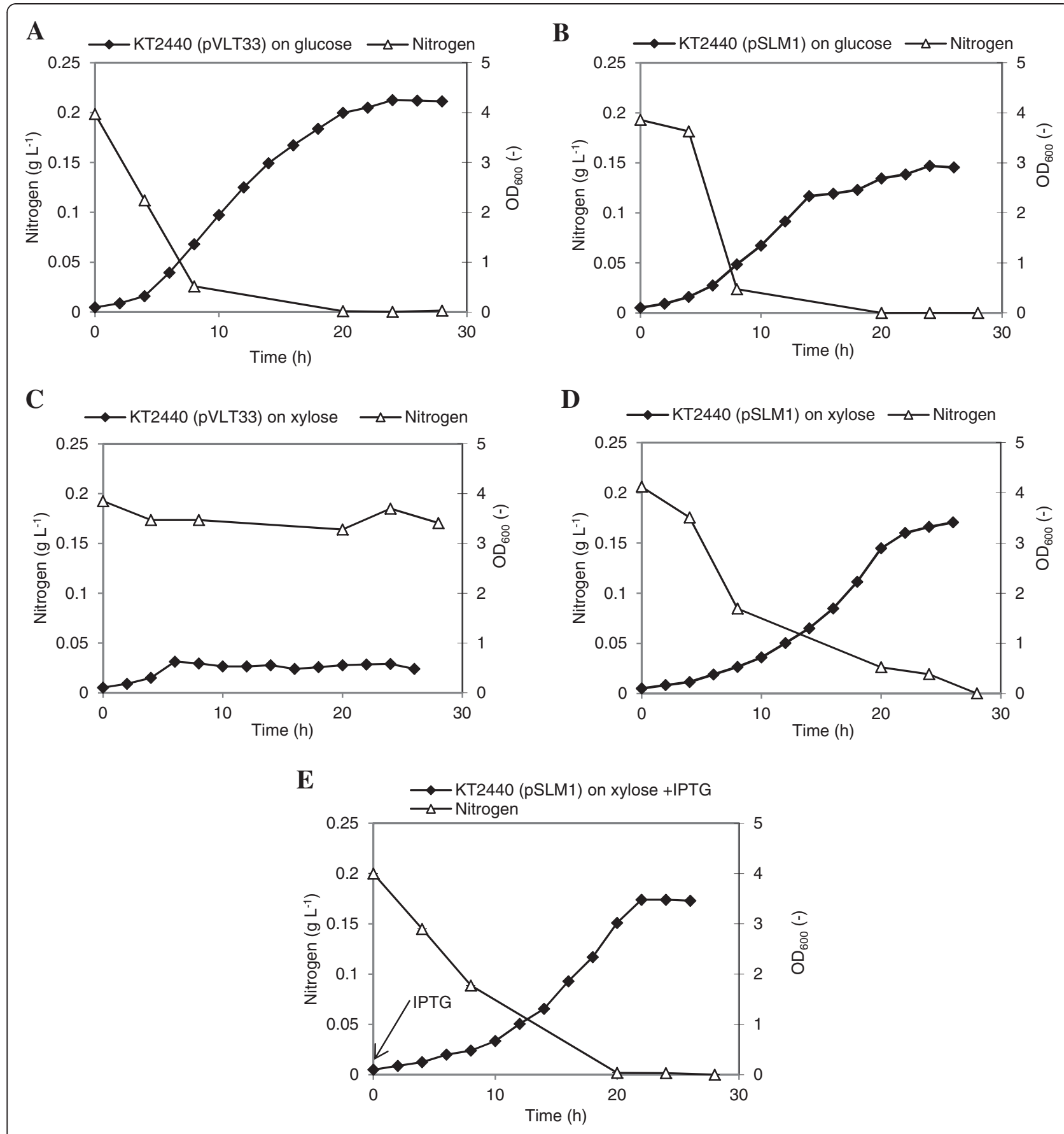

Figure 1 Growth of the P. putida KT2440 recombinants in shake flasks on E2 minimal medium containing $10 \mathrm{~g} \mathrm{~L}^{-1}$ glucose or xylose as the sole carbon source. The arrow represents the addition of IPTG. The experiments were performed in replicate flasks. Data points are the averages of the results of duplicate measurements.

KT2440 on xylose. To have better controlled growth, further experiments were performed in bioreactors.

\section{Growth of $P$. putida KT2440 (pSLM1) on xylose in} the bioreactor

P. putida KT2440 (pSLM1) was grown on E2 medium with $10 \mathrm{~g} \mathrm{~L}^{-1}$ xylose in a $3.7 \mathrm{~L}$ laboratory bioreactor.
Figure 2 shows that the KT2440 (pSLM1) cells utilized xylose as the sole carbon source with a maximum specific growth rate of $0.24 \mathrm{~h}^{-1}$. The growth stopped due to nitrogen limitation after $13 \mathrm{~h}$ of cultivation. Afterwards the biomass increased only slightly from $2.2 \mathrm{~g} \mathrm{~L}^{-1}$ to maximum $2.7 \mathrm{~g} \mathrm{~L}^{-1}$ at $28 \mathrm{~h}$. Even though nitrogenlimitation was reached, xylose was further consumed 


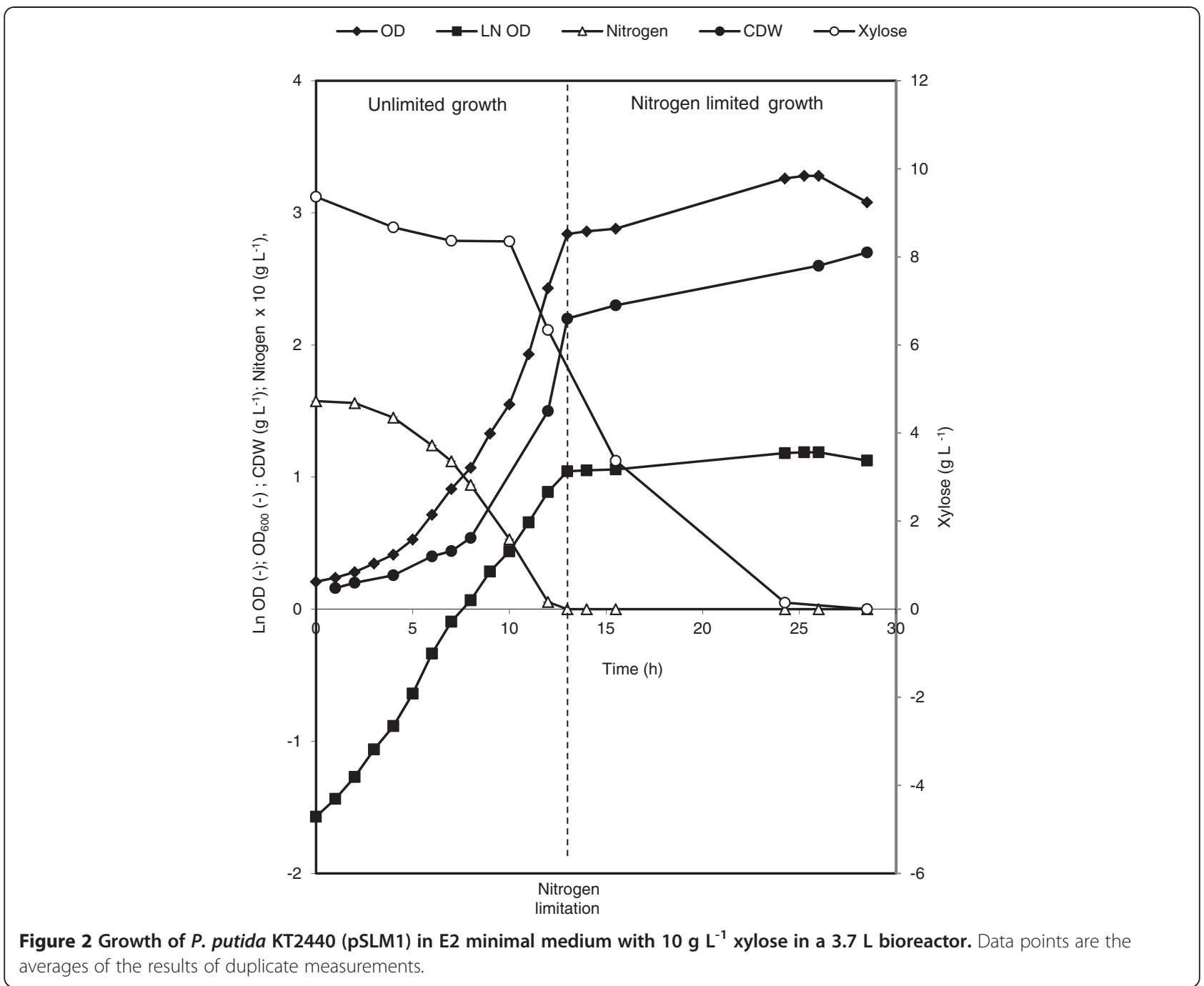

and finally only a tiny amount was left in the medium (Figure 2). The biomass yield from xylose was about $0.5 \mathrm{~g} \mathrm{~g}^{-1}$ upon nitrogen limitation (13 h of cultivation), and about $0.27 \mathrm{~g} \mathrm{~g}^{-1}$ upon the xylose depletion. The consumed xylose after nitrogen completion may have been used for cell maintenance and/or by-products such as acetic acid. Indeed, large amounts of acetic acid were detected from the beginning of the growth, in the range of several hundred milligrams per liter. The culture was also assayed for PHA content at different time points. Only trace amounts (up to $0.3 \% \mathrm{w} \mathrm{w}^{-1}$ ) of PHA were detected using xylose as the sole carbon source, which enables to use xylose as growth substrate for the production of tailor-made mcl-PHAs.

To confirm the enzymatic activities of XylA and XylB, cells were harvested at the early exponential growth phase $\left(\mathrm{OD}_{600}\right.$ of about 0.5). Samples without substrates and samples without cell-free extracts were used as negative controls, while $E$. coli W3110 cells grown on E2 with xylose were used as the positive control. The specific activities of xylose isomerase and xylulokinase measured in $P$. putida KT2440 (pSLM1) were $1.47 \mathrm{U}$ and $0.97 \mathrm{U}$, respectively, whereas no significant activites were observed in the negative controls (Table 1). The activities obtained here were in the same range as those found in wild-type E. coli W3110 (Table 1). These results confirmed that both XylA and XylB were active in $P$. putida KT2440. The enzymatic activities of XylA and XylB were also found for the non-induced cultures, thus, induction by IPTG is not needed for the expression of

Table 1 Enzymatic activities of XylA and XylB in P. putida KT2440 (pSLM1)

\begin{tabular}{lccccc}
\hline & \multicolumn{2}{c}{ Negative control } & & \multicolumn{2}{c}{ Sample } \\
\cline { 2 - 3 } \cline { 6 - 7 } & $\begin{array}{c}\text { No } \\
\text { substrate }\end{array}$ & $\begin{array}{c}\text { No } \\
\text { cells }\end{array}$ & & $\begin{array}{c}E \text {. coli } \\
\text { W3110 }\end{array}$ & $\begin{array}{c}\text { P. putida } \\
\text { (pSLM1) }\end{array}$ \\
\hline XylA act. $(U)$ & 0.07 & 0.33 & & 1.79 & 1.47 \\
XylB act. $(U)$ & 0.26 & 0.12 & & 1.39 & 0.97
\end{tabular}

$\boldsymbol{U}$ : One unit is defined as $1 \mu$ mole of consumed NADH $\min ^{-1}$. 
$x y l A$ and $x y l B$ genes and was therefore omitted in the following experiments.

\section{PHA production in KT2440 (pSLM1) by sequential-feeding} of xylose and fatty acid

Nitrogen limitation is known to promote PHA accumulation [1]. It has been demonstrated that nitrogen limitation can lead to a strong induction of phaG encoding a transacylase, resulting in mcl-PHA accumulation from carbohydrate in P. putida KT2440 [24]. Thus, in the experiments performed in mini-reactors the amount of nitrogen present in E2 medium was decreased to $20 \%$ (namely 0.2NE2 medium) to obtain the best conditions for mcl-PHA accumulation. As expected, KT2440 (pVLT33) did not show any growth on xylose (Table 2, culture A), similar as observed in Figure 1. KT2440 (pSLM1) exhibited a maximal specific growth rate of $0.24 \mathrm{~h}^{-1}$ on xylose with a maximum $\mathrm{OD}_{600}$ of 0.99 (Table 2, culture B). No PHA was detected for KT2440 (pSLM1) on xylose.

To test whether the recombinant is able to accumulate mcl-PHA from related carbon source (e. g. octanoic acid), KT2440 (pSLM1) was pre-cultured in E2 minimal medium with xylose as the sole carbon source and then transferred into a bioreactor containing 0.2NE2 medium with $10 \mathrm{mM}$ octanoic acid as the sole carbon source (Table 2, culture C). Samples were taken regularly and the cellular PHA content was determined. It was found that KT2440 (pSLM1) was able to accumulate mcl-PHA to $21 \%\left(\mathrm{w} \mathrm{w}^{-1}\right)$ after $33 \mathrm{~h}$ of cultivation.
The above results demonstrate that the recombinant strain KT2440 (pSLM1) kept the ability to synthesize PHA from fatty acids, but could not do so from xylose. This allows sequential feeding of xylose and fatty acids to obtain tailor-made mcl-PHA biosynthesis, namely, first using an inexpensive carbon source for cell growth and then adding the appropriate mcl-PHA precursor to allow the polymer accumulation. The sequential feeding strategy enables production of a tailor-made mcl-PHA according to the supplied fatty acid. Octanoic acid was tested here as mcl-PHA precursor in order to obtain poly(3-hydroxyoctanoate) accumulation. We first investigated the influence of linear feeding of octanoic acid at different growth stages on PHA synthesis. Four minireactors in parallel were inoculated using the same P. putida KT2440 (pSLM1) preculture grown in E2 medium with $1.8 \mathrm{~g} \mathrm{~L}^{-1}$ xylose. In cultures $\mathrm{D}$ and $\mathrm{E}$ linear feeding of $0.072 \mathrm{~g} \mathrm{~L}^{-1} \mathrm{~h}^{-1}$ of octanoic acid was initiated at $\mathrm{OD}_{600}$ of 0.5 ( $8 \mathrm{~h}$ of batch cultivation) and $1.0(10 \mathrm{~h}$ of batch cultivation), respectively. Both cultures showed a similar maximum specific growth rate of $0.24 \mathrm{~h}^{-1}$ (Table 2). The nitrogen limitation was reached after $11 \mathrm{~h}$ and xylose was depleted after $12 \mathrm{~h}$ for both cultures. The maximum accumulation of PHA was found to be $12.1 \% \mathrm{w} \mathrm{w}^{-1}$ and $16.2 \% \mathrm{w} \mathrm{w}^{-1}$ for $\mathrm{D}$ and $\mathrm{E}$, respectively, after about $20 \mathrm{~h}$ of cultivation (Table 2). The obtained results suggested that PHA can be produced in P. putida KT2440 (pSLM1) by sequential feeding of xylose and fatty acids. The exponential phase ended at $\mathrm{OD}_{600}$ of 1.0 due to nitrogen limitation. Linear feeding at the end of the exponential growth phase in the batch $\left(\mathrm{OD}_{600}\right.$ of

Table 2 PHA production in batch and fed-batch fermentations

\begin{tabular}{|c|c|c|c|c|c|c|c|c|c|c|c|}
\hline \multirow[t]{2}{*}{ Entry } & \multirow[t]{2}{*}{ Strains } & \multirow{2}{*}{$\begin{array}{c}\text { Fermentation } \\
\text { type }\end{array}$} & \multicolumn{2}{|c|}{ Carbon source } & \multirow{2}{*}{$\begin{array}{l}\text { Feeding } \\
\text { type/ } \\
\text { duration }\end{array}$} & \multirow{2}{*}{$\begin{array}{l}\text { Feeding } \\
\text { phase }\end{array}$} & \multirow[t]{2}{*}{ Flow } & \multirow{2}{*}{$\begin{array}{l}\text { Total } \\
\text { amount } \\
\text { of fed } \\
\text { octanoic } \\
\text { acid }\end{array}$} & \multirow[t]{2}{*}{$O D_{600}$} & \multirow[t]{2}{*}{$\mu_{\max }\left(h^{-1}\right)$} & \multirow{2}{*}{$\begin{array}{c}\text { PHA } \\
\text { content } \\
\left(\% w^{-1}\right.\end{array}$} \\
\hline & & & $\begin{array}{l}\text { growth } \\
\text { substrate }\end{array}$ & $\begin{array}{c}\text { PHA } \\
\text { precusor }\end{array}$ & & & & & & & \\
\hline A & $\begin{array}{l}\text { KT2440 } \\
\text { (pVLT33) }\end{array}$ & Batch & xylose & - & - & - & - & & no growth & - & - \\
\hline B & $\begin{array}{l}\text { KT2440 } \\
\text { (pSLM1) }\end{array}$ & Batch & xylose & - & - & - & - & & 0.99 & 0.24 & 0.3 \\
\hline C & $\begin{array}{l}\text { KT2440 } \\
\text { (pSLM1) }\end{array}$ & Batch & octanoic acid & - & - & - & - & $1.44 \mathrm{~g} \mathrm{~L}^{-1}$ & 2.77 & 0.35 & 21.0 \\
\hline$D$ & $\begin{array}{l}\text { KT2440 } \\
(p S L M 1)\end{array}$ & Fed-Batch & xylose & $\begin{array}{l}\text { octanoic } \\
\text { acid }\end{array}$ & linear/12 h & $\begin{array}{l}\operatorname{mid}_{\text {exp. }}^{(1)} \\
\end{array}$ & $0.072 \mathrm{~g} \mathrm{~L}^{-1} \mathrm{~h}^{-1}$ & $0.87 \mathrm{~g} \mathrm{~L}^{-1}$ & 1.48 & 0.24 & 12.1 \\
\hline E & $\begin{array}{l}\text { KT2440 } \\
(\mathrm{pSLM1})\end{array}$ & Fed-Batch & xylose & $\begin{array}{l}\text { octanoic } \\
\text { acid }\end{array}$ & linear/8 h & $\begin{array}{l}\text { end } \\
\text { exp. }\end{array}$ & $0.072 \mathrm{~g} \mathrm{~L}^{-1} \mathrm{~h}^{-1}$ & $0.58 \mathrm{~g} \mathrm{~L}^{-1}$ & 1.52 & 0.25 & 16.2 \\
\hline $\mathrm{F}$ & $\begin{array}{l}\text { KT2440 } \\
(\mathrm{pSLM1})\end{array}$ & Fed-Batch & xylose & $\begin{array}{l}\text { octanoic } \\
\text { acid }\end{array}$ & linear/4 h & $\begin{array}{l}\text { end } \\
\text { exp. }\end{array}$ & $0.288 \mathrm{~g} \mathrm{~L}^{-1} \mathrm{~h}^{-1}$ & $1.15 \mathrm{~g} \mathrm{~L}^{-1}$ & 1.4 & 0.25 & 20 \\
\hline G & $\begin{array}{l}\text { KT2440 } \\
\text { (pSLM1) }\end{array}$ & Batch & $\begin{array}{c}\text { xylose + octanoic } \\
\text { acid }\end{array}$ & $\begin{array}{l}\text { octanoic } \\
\text { acid }\end{array}$ & - & - & - & $1.44 \mathrm{~g} \mathrm{~L}^{-1}$ & 2.13 & 0.27 & 28.7 \\
\hline
\end{tabular}

The cells were grown in $0.2 \mathrm{NE} 2$ minimal media supplemented with different carbon sources in $1 \mathrm{~L}$ mini-bioreactors with a working volume of $800 \mathrm{~mL}$. Samples were taken regularly to measure growth, nitrogen concentration, carbon source present in the medium and PHA contents. Data points are the averages of duplicate measurements.

(1): Feeding started at the middle of exponential batch phase, $\mathrm{OD}_{600}$ of 0.5 .

${ }^{(2)}$ : Feeding started at the end of exponential batch phase, $\mathrm{OD}_{600}$ of 1. 
1.0) gave a better yield of PHA compared to that at the mid-exponential growth phase $\left(\mathrm{OD}_{600}\right.$ of 0.5$)$. This lower yield obtained in the latter can be explained by consumption of octanoic acid for growth rather than for PHA accumulation during the mid-exponential phase.

To increase PHA accumulation, the feeding rate was increased from $0.072 \mathrm{~g} \mathrm{~L}^{-1} \mathrm{~h}^{-1}$ to $0.288 \mathrm{~g} \mathrm{~L}^{-1} \mathrm{~h}^{-1}$ of octanoic acid. Culture $\mathrm{F}$ was grown on $0.2 \mathrm{NE} 2$ with $1.8 \mathrm{~g} \mathrm{~L}^{-1}$ xylose and feeding started at the end of the exponential growth phase with a feeding rate of $0.288 \mathrm{~g} \mathrm{~L}^{-1} \mathrm{~h}^{-1}$ of octanoic acid. For comparison, culture $G$ was supplemented with $1.8 \mathrm{~g} \mathrm{~L}^{-1}$ xylose and $1.44 \mathrm{~g} \mathrm{~L}^{-1}$ octanoic acid from the beginning on (batch culture on mixed carbon sources). Using culture $\mathrm{F}$ as an example, Figure 3 represents a typical behavior of cells regarding growth and PHA synthesis. After $7 \mathrm{~h}$ and $14.5 \mathrm{~h}$ of cultivation, nitrogen and xylose were depleted, respectively. When cells entered the nitrogen limitation phase a linear feeding of octanoic acid was started for $4 \mathrm{~h}$ and then stopped. PHA synthesis was detected after $2 \mathrm{~h}$ of feeding and increased linearly to $17.6 \% \mathrm{w} \mathrm{w}^{-1}$ during the following $14 \mathrm{~h}$. Only a slight increase of PHA content to about $20 \% \mathrm{w} \mathrm{w}^{-1}$ was found after further incubation up to $43 \mathrm{~h}$. The concentration of octanoic acid measured in the culture increased with feeding time, after $7.5 \mathrm{~h}$ from the beginning of the feeding about $0.369 \mathrm{~g} \mathrm{~L}^{-1}$ octanoic acid was detected; afterwards it continuously decreased. At the end of the cultivation, after $48.5 \mathrm{~h}$, the remaining octanoic acid was only $0.069 \mathrm{~g} \mathrm{~L}^{-1}$. A maximal yield of mcl-PHA from octanoic acid of $0.37 \mathrm{~g}$ mcl-PHA $\mathrm{g}^{-1}$ octanoic acid was obtained by considering the increase of PHA from $6.6 \% \mathrm{w} \mathrm{w}^{-1}$ to $20 \% \mathrm{w} \mathrm{w}^{-1}$ in relation to the consumption of octanoic acid from $0.369 \mathrm{~g} \mathrm{~L}^{-1}$ to $0.086 \mathrm{~g} \mathrm{~L}^{-1}$.

GC analysis revealed that the main monomer component of the synthesized PHA was 3-hydroxyoctanoate $\left(87 \% \mathrm{w} \mathrm{w}^{-1}\right)$ and no 3-hydroxydecanoate was detected. These results confirm that the detected PHA is mainly from octanoic acid. Since the main monomer unit of PHA produced from carbohydrates is 3-hydroxydecanoate in KT2440 [25,26], it is very unlikely that xylose was used for PHA synthesis. The sequential feeding strategy using $x y-$ lose as growth substrate and octanoic acid as mcl-PHA precursor enabled production of a controlled mcl-PHA production.

\section{Discussion}

\section{Growth of KT2440 on xylose}

A recombinant $P$. putida KT2440 strain was constructed that could efficiently utilize xylose. The introduction of xylose isomerase (XylA) and xylulokinase (XylB) was essential and sufficient for the utilization of xylose and a growth rate of $0.24 \mathrm{~h}^{-1}$ was routinely obtained. Previously, it has been reported that a so called "laboratory evolution" was necessary to improve the growth rate of P. putida S12 (xylAB) on xylose from $0.01 \mathrm{~h}^{-1}$ to $0.35 \mathrm{~h}^{-1}$

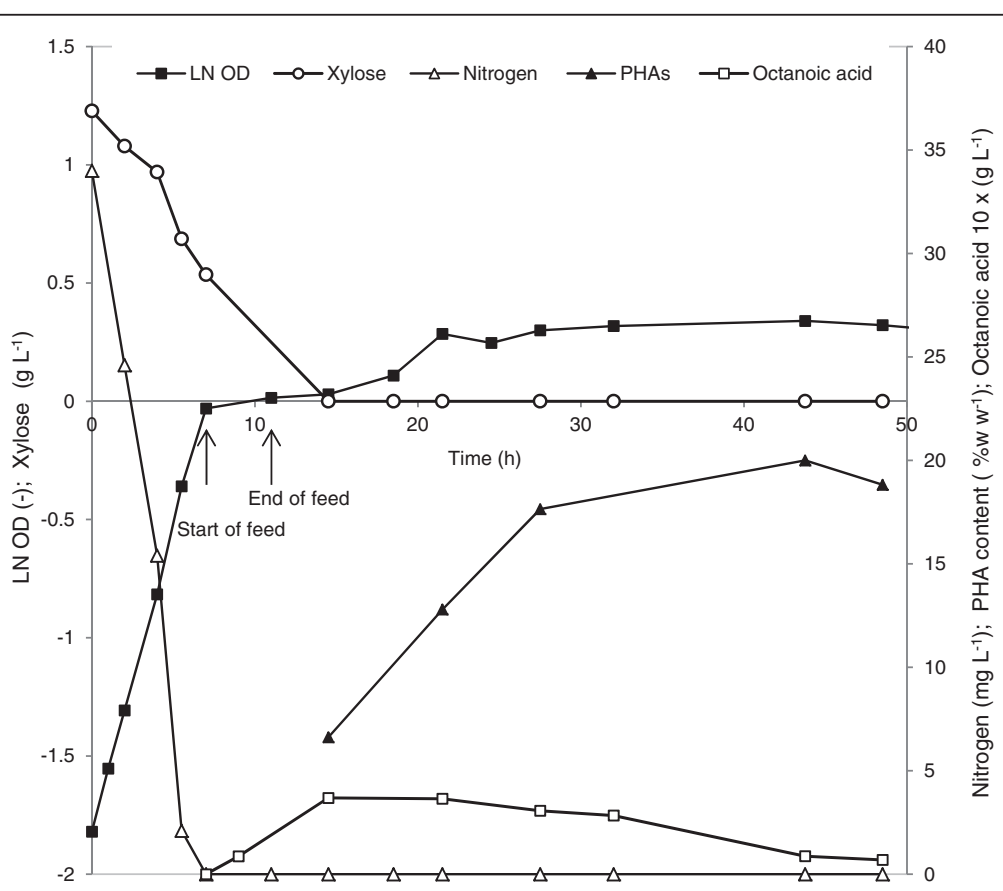

Figure 3 Fed-batch experiment of $P$. putida KT2440 (pSLM1) grown on $0.2 \mathrm{NE} 2$ medium containing $1.8 \mathrm{~g} \mathrm{~L}^{-1}$ xylose with linear feeding of $0.288 \mathrm{~g} \mathrm{~L}^{-1} \mathrm{~h}^{-1}$ octanoic acid at $\mathrm{OD}_{600}$ of 1 for $4 \mathrm{~h}$. Nitrogen $(\Delta)$, octanoic acid ( $\square$ ) and xylose $(O)$ concentrations were measured. The logarithmic growth is represented by filled squares $(\mathbf{-})$ and the PHA accumulation by filled triangles $(\mathbf{\Lambda})$. Data points are the averages of the results of duplicate measurements. 
and to obtain a yield of $0.52 \mathrm{~g}$ CDW per g xylose [23]. The laboratory evolution is an adoption process by growing the cells consecutively in a fresh medium containing the unfavorable carbon source. The "laboratory evolution" was not needed for the KT2440 recombinant to grow on xylose. This difference could be attributed to the different physiological background/metabolic fluxes of KT2440 and S12. It has been reported that in $P$. putida a complete pentose phosphate pathway is present $[23,27]$ (Figure 4) as well as the key enzymes for mclPHA accumulation [28]. Our study demonstrated that the enzymes responsible for converting xylose to the entry intermediate xylulose-5-phosphate of PP pathway are missing in P. putida. By introducing the relevant enzymes XylA and XylB, P. putida KT2440 was able to utilize xylose.

In addition, the recombinant $P$. putida KT2440 appeared to have an efficient xylose uptake system. Similarly, $P$. putida S12 carrying D-xylonate dehydratase has been reported to grow on xylose without expressing any xylose transporter [29]. Since pentose and hexose transporters have been shown to be promiscuous [30], it is possible that xylose uptake can be accomplished by glucose uptake systems in strain KT2440 (xylAB). Many bacteria also possess non-specific transporters. Indeed, many sugars are transported into E. coli by phosphoenolpyruvatedependent phosphotransferase systems (PTS) like glucose, mannose, fructose, and $\mathrm{N}$-acetylglucosamine [31]. In this study, no specific xylose transporters such as XylE or XylFGH were needed for growth of KT2440 ( $x y l A B)$ on xylose. Thus, it is also possible that xylose entered the cell through the PTS system present in P. putida in a similar way as reported for fructose [32]. Xylose, after uptake into the cell, is isomerized by xylose isomerase to xylulose, which is then converted by xylulokinase to xylulose 5-phosphate. This phosphorylated derivate is then catabolized by the pentose phosphate pathway. In comparison to growth on glucose, the growth of $P$. putida KT2440 $(x y l A B)$ on xylose exhibited a similar specific growth rate of $0.24 \mathrm{~h}^{-1}$ (Figure 1). This demonstrated that the uptake and the catabolic rate of xylose by the recombinant P. putida KT2440 (pSLM1) is in the same range as that of glucose.

\section{PHA production by sequential feeding}

The biosynthesis of mcl-PHA is mainly studied for fluorescent pseudomonads, e.g. P. putida KT2440. Strain KT2440 is characterized by a wide metabolic and physiologic versatility and is able to accumulate mclPHA from glucose [33]. In this study, we demonstrated

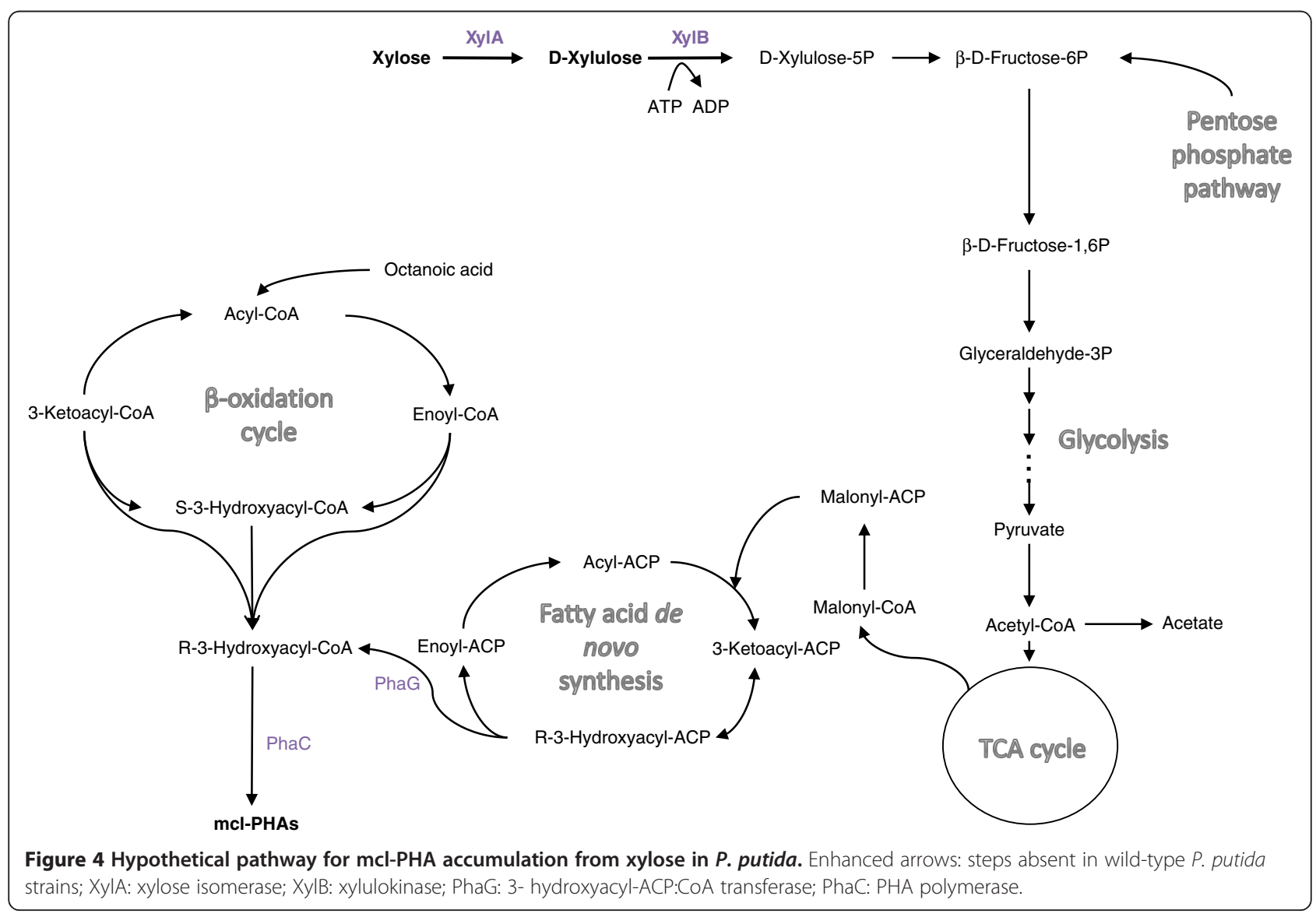


that mcl-PHA biosynthesis on xylose does not occur when $x y l A$ and $x y l B$ are expressed even under nitrogen limitation, perhaps because the expression of $x y l A B$ channels the metabolic flux to central metabolism such as TCA cycle for cell maintenance or/and to production of side products like acetate, rather than to PHA synthesis (Figure 4).

Up to now, there has been no report on mcl-PHA production by using xylose as the growth substrate. Substrate cost make up a large proportion of the total production cost of PHA. Fatty acids are generally much more expensive than lignocellulose hydrolysates (such as xylose) and often toxic to the cells at relatively low concentrations and, for some of them, do not support fast growth rates. Xylose is in a similar price range like cane molasses and half the price of glucose [34], consequently, sequential-feeding strategies are a valid option to reduce the production cost $[35,36]$. Sequential-feeding consists of using on one hand cheap carbohydrates for achieving a large biomass and on the other hand fatty acids as mcl-PHA precursors to produce tailor-made mcl-PHAs.

In this study, xylose was used for cell growth in the first step, and then octanoate was supplied to synthesize mcl-PHA in the second step under nitrogen limitation. This sequential feeding process allowed a tailor-made mcl-PHA accumulation of up to $20 \%\left(\mathrm{w} \mathrm{w} \mathrm{w}^{-1}\right)$ under notyet-optimized conditions. When $1.44 \mathrm{~g} \mathrm{~L}^{-1}$ octanoate was employed alone for growth and PHA production (Table 2, entry C), lower PHA content (about $21 \% \mathrm{w} \mathrm{w}^{-1}$ ) was obtained than that from using both xylose and $1.44 \mathrm{~g} \mathrm{~L}^{-1}$ octanoate (Table 2, entry G, about $28.7 \% \mathrm{w} \mathrm{w}^{-1}$ ), even though the growth rate and the final cell density reached in entry $C$ were higher than those in entry G. These results suggest that xylose is not a substrate as good as octanoate for growth of KT2440, however, it can facilitate the PHA production by being a substrate for growth and allowing only octanoate to be converted to PHA.

In this study, P. putida KT2440 (pSLM1) showed a biomass yield from xylose at $0.50 \mathrm{~g} \mathrm{~g}^{-1}$, which is similar to what has been previously reported $0.52 \mathrm{~g} \mathrm{~g}^{-1}$ for $P$. putida S12 (xylAB) [23]. Previously, Kim and co-workers used a sequential feeding strategy to maximize the PHA production in P. putida using glucose as growth substrate and then octanoic acid for PHA accumulation [37]. A yield of $0.4 \mathrm{~g}$ mcl-PHA g $\mathrm{g}^{-1}$ octanoic acid was reached [37], similar to the yield of $0.37 \mathrm{~g}$ mcl-PHA g $^{-1}$ octanoic acid obtained in this study by sequential feeding of xylose and octanoic acid. However, it has also been reported that the yield of mcl-PHAs from fatty acids such as nonanoic acid could achieve 0.66 to $0.69 \mathrm{~g}^{-1}$ mcl-PHA g nonanoic acid by co-feeding glucose [36]. Therefore, further optimization of the sequential- feeding process is needed to increase the yield of tailormade mcl-PHAs.

\section{Conclusion}

Introduction of $x y l A B$ from $E$. coli into $P$. putida KT2440 was sufficient to allow the recombinant to efficiently utilize xylose as the sole carbon source. Experiments performed in bioreactors showed that XylA and XylB were active in P. putida KT2440. The recombinant did not produce mcl-PHA from xylose, thus enabled production of a tailor-made mcl-PHA of up to $20 \%\left(\mathrm{w} \mathrm{w}^{-1}\right)$ by sequential-feeding of xylose and octanoate. A maximal yield of $0.37 \mathrm{~g}$ mcl-PHA $\mathrm{g}^{-1}$ octanoic acid was obtained with PHA containing mainly 3-hydroxyoctanoate monomers $\left(87 \% \mathrm{w} \mathrm{w}^{-1}\right)$. Sequential feeding of relatively cheap carbohydrates and expensive fatty acids is a practical way to achieve more cost-effective mcl-PHA production. Optimization of initiation, rate and duration of feeding should be performed to achieve a higher yield and higher productivity of mcl-PHA. Furthermore, an optimized growth conditions will undoubtedly contribute to the economic feasibility of mcl-PHA production from renewable feedstock.

\section{Methods}

\section{Bacterial strains and plasmids}

Strains and plasmids used in this study are listed in Table 3.

\section{Chemicals}

All chemicals were purchased from Sigma-Aldrich (Buchs, Switzerland). The oligonucleotides were purchased from Microsynth (Balgach, Switzerland). The restriction enzymes were purchased from Fermantas $\mathrm{GmbH}$ (Nunningen, Switzerland) or New England Biolabs (Allschwil, Switzerland).

\section{Cloning, characterization and expression genes involved in xylose utilization \\ Construction of PSLM1}

The chromosomal DNA of E. coli W3110 was extracted and used as the template for cloning of $x y l A B$ (GenElute $^{\mathrm{TM}}$, bacterial Genomic DNA kit, Sigma-Aldrich). The fragment containing both $x y l A$ and $x y l B$ was amplified using the following primers: PFXylA (5' CCGAatTCTGGagTTCAATATG 3') and PRXylB (5' GATAAGCTTTACGCCATTAATG 3'). The amplified fragment was purified from agarose gel (GenElute $^{\mathrm{TM}}$, Gel Extraction kit, Sigma Aldrich), and further digested with EcoRI and HindIII restriction enzymes. This digested fragment was ligated into the shuttle vector pVLT33 [39], which was cut with the same restriction enzymes. The ligation solution was transformed into E. coli JM109 and the recombinants were 
Table 3 Strains and plasmids used in this study

\begin{tabular}{|c|c|c|}
\hline Strain or plasmid & Relevant characteristics & References \\
\hline \multicolumn{3}{|l|}{ Strains } \\
\hline P. putida KT2440 & Prototrophic, reference strain & http://openwetcare.org/wiki/E._coli_genotypes \\
\hline E. coli W3110 & Wild type, $x y / A B$ donor & http://openwetcare.org/wiki/E._coli_genotypes \\
\hline E. coli JM109 & $\begin{array}{l}\text { endA1, glnV44, gyrA96, thi-1, } \mathrm{mcrB}^{+}, \text {hsdR17 }\left(\mathrm{r}_{\mathrm{k}}^{-}, \mathrm{m}_{\mathrm{k}}^{+}\right) \text {, relA1, supE44, } \\
{\left[\mathrm{F}^{\prime} \text { traD36 proAB }{ }^{+} \text {lacl }{ }^{9} \text { lacZ } \mathrm{M} 15\right]}\end{array}$ & http://openwetcare.org/wiki/E._coli_genotypes \\
\hline E. coli HB101 & $\mathrm{F}^{-}$, hsdS20 (r- $\left.\mathrm{r}_{\mathrm{B}}^{-}\right)$recA13, ara-14, proA2, lacY1, galK2, xyl-5, mtl-1, rpsL20 $\left(\mathrm{Sm}^{\mathrm{R}}\right)$. & http://openwetcare.org/wiki/E._coli_genotypes \\
\hline \multicolumn{3}{|l|}{ Plasmids } \\
\hline RK600 & $\mathrm{Cm}^{r}$, ColE1, oriV, RK2, mob+, tra+ & [38] \\
\hline pVLT33 & $\mathrm{Km}^{r}$, Ptac, MCS of pUCP18, hybrid broad-host-range expression vector & [39] \\
\hline pSLM1 & $x y / A$ and $x y / B$ cloned into pVLT33 & this study \\
\hline
\end{tabular}

selected on a Luria broth agar plate with $50 \mu \mathrm{g} \mathrm{mL} \mathrm{m}^{-1}$ kanamycin, $1 \mathrm{M}$ bromo-chloro-indolyl-galactopyranoside (X-gal), and $1 \mathrm{mM}$ isopropyl $\beta$-D-1-thiogalactopyranoside (IPTG). The obtained plasmid (insert + vector) was named pSLM1. The nucleotide sequence of $x y l A B$ was analyzed and confirmed by GATC Biotech AG (Konstanz, Germany).

\section{Introduction of pSLM1 into P. putida KT2440}

The obtained plasmid pSLM1 was introduced into P. putida KT2440 by triparental mating [40]. E. coli HB101 (RK600) [38] was used as the helper strain. E. coli JM109 (pSLM1) was the donor strain and $P$. putida KT2440 was the acceptor strain. The $P$. putida KT2440 recombinants were selected on E2 medium (see below) containing $0.2 \%$ citrate and $25 \mu \mathrm{g} \mathrm{mL}^{-1}$ kanamycin. In analogy, the empty vector pVLT33 was also introduced into $P$. putida KT2440 as a control.

\section{Growth conditions}

E2 minimal medium supplemented with different carbon sources (xylose, glucose or octanoic acid) was used throughout the whole study. This medium contains the following components: $\mathrm{NaNH}_{4} \mathrm{HPO}_{4} .4 \mathrm{H}_{2} \mathrm{O} 3.5 \mathrm{~g} \mathrm{~L}^{-1}$, $\mathrm{KH}_{2} \mathrm{PO}_{4} 3.7 \mathrm{~g} \mathrm{~L}^{-1}, \mathrm{~K}_{2} \mathrm{HPO}_{4} 7.5 \mathrm{~g} \mathrm{~L} \mathrm{~L}^{-1}$, dissolved in water, and $1 \mathrm{~mL} \mathrm{~L}^{-1} \mathrm{MgSO}_{4} .7 \mathrm{H}_{2} \mathrm{O} 246.5 \mathrm{~g} \mathrm{~L}^{-1}$ and $1 \mathrm{~mL} \mathrm{~L}^{-1}$ of trace element (TE) dissolved in $1 \mathrm{M} \mathrm{HCl}$ were added. TE contains $\mathrm{FeSO}_{4} .7 \mathrm{H}_{2} \mathrm{O} 2.78 \mathrm{~g} \mathrm{~L}^{-1}$, $\mathrm{CaCl}_{2} .2 \mathrm{H}_{2} \mathrm{O} \quad 1.47 \mathrm{~g} \mathrm{~L}^{-1}, \mathrm{MnCl}_{2} .4 \mathrm{H}_{2} \mathrm{O} \quad 1.98 \mathrm{~g} \mathrm{~L}^{-1}$, $\mathrm{CoCl}_{2} \cdot 6 \mathrm{H}_{2} \mathrm{O} \quad 2.38$ g L ${ }^{-1}, \mathrm{CuCl}_{2} \cdot 2 \mathrm{H}_{2} \mathrm{O} \quad 0.17$ g L $\mathrm{L}^{-1}$, $\mathrm{ZnSO}_{4} .7 \mathrm{H}_{2} \mathrm{O} 0.29 \mathrm{~g} \mathrm{~L}^{-1}$. In some experiments, the nitrogen content of the E2 medium was reduced to $20 \%$ $(0.2 \mathrm{NE} 2)$ as indicated in the results section. If necessary, $25 \mu \mathrm{g} \mathrm{mL} \mathrm{m}^{-1}$ kanamycin was added to the culture medium.

\section{Growth in shake flasks}

The recombinant $P$. putida KT2440 (pSLM1) was precultured in $100 \mathrm{~mL}$ of $\mathrm{E} 2$ medium containing $10 \mathrm{~g} \mathrm{~L}^{-1}$ xylose and $25 \mu \mathrm{g} \mathrm{mL} \mathrm{m}^{-1}$ kanamycin. The preculture in the exponential growth phase was then transferred to fresh E2 medium containing xylose and kanamycin with a dilution of 1:20. This transfer was repeated twice to allow cells to adapt to xylose. P. putida KT2440 (pVLT33) was used as control. The P. putida cells were grown at $30^{\circ} \mathrm{C}$ with an agitation of $150 \mathrm{rpm}$ in $1 \mathrm{~L}$ baffled shake flasks.

E. coli cells were grown at $37^{\circ} \mathrm{C}$ in either $\mathrm{LB}$ medium or E2 medium containing xylose as the sole carbon source. Samples were taken and stored at $-20^{\circ} \mathrm{C}$ as indicated in the Results section for the determination of $x y-$ lose isomerase and xylulokinase activities.

\section{Batch culture in 3.7 L reactor}

The bioreactor study was carried out in a $3.7 \mathrm{~L}$ laboratory bioreactor (KLF 2000, Bioengineering, Wald, Switzerland) with a working volume of 2 L. Medium E2 supplemented with $10 \mathrm{~g} \mathrm{~L}^{-1}$ xylose as the sole carbon source was used. The batch bioreactor was inoculated with $300 \mathrm{~mL}$ of preculture having an $\mathrm{OD}_{600}$ of 2.10 and containing exactly the same medium as the one present in the bioreactor. The agitation was set at $750 \mathrm{rpm}$. The temperature was controlled at $30^{\circ} \mathrm{C}$ and the $\mathrm{pH}$ was maintained at 7.0 by automated addition of $4 \mathrm{M}$ $\mathrm{KOH}$ or $2 \mathrm{M} \mathrm{H}_{2} \mathrm{SO}_{4}$. The dissolved oxygen tension was monitored continuously with an oxygen probe and kept at above $20 \%$ of air saturation (with a flow of $1 \mathrm{v} \mathrm{v}^{-1} \min ^{-1}$ ).

\section{Batch culture in 1 L mini-reactors}

In order to obtain a nitrogen limited growth more rapidly, 0.2NE2 medium was used in these experiments. Four mini-reactor cultures (A, B, C and D) were grown in parallel in Multifors-Multiple benchtop bioreactors (Infors AG, Bottmingen, Switzerland). Temperature was controlled at $30^{\circ} \mathrm{C}$ and $\mathrm{pH}$ was maintained at 7.0 by automated addition of $4 \mathrm{M} \mathrm{KOH}$ or $2 \mathrm{M} \mathrm{H}_{2} \mathrm{SO}_{4}$. The dissolved oxygen tension was monitored continuously with an oxygen probe and kept at $30 \%$ of air saturation. 
Each reactor was inoculated using the pre-culture which was prepared as described above "Growth in shake flasks". The initial $\mathrm{OD}_{600}$ in bioreactors was about 0.08 . Kanamycin was added to a final concentration of $25 \mu \mathrm{g} \mathrm{mL}^{-1}$ when the recombinant was cultivated. Octanoic acid with different concentrations was fed to the bioreactors at different growth stages of the batches, as described in the Results section.

\section{Enzymatic assays}

The cell pellets from batch culture were washed twice with $250 \mathrm{mM}$ Tris- $\mathrm{HCl}$ buffer $\mathrm{pH} 7.5$, and then lysed by the addition of lytic solution according to the manufacture's instruction (CellLytic ${ }^{\text {TM }}$ B Cell Lysis Reagent, Sigma-Aldrich, St. Louis, MO, USA). The samples were centrifuged at $20^{\prime} 000 \mathrm{~g}$ for $3 \mathrm{~min}$ in an Eppendorf centrifuge. The supernatant is referred as cell-free extract (CFE).

Xylose isomerase (EC 5.3.1.5) was measured in a solution containing $0.2 \mathrm{mM}$ NADH, $50 \mathrm{mM}$ xylose, $10 \mathrm{mM}$ $\mathrm{MgSO}_{4}, 0.5 \mathrm{U}$ sorbitol dehydrogenase, and $30 \mu \mathrm{L} \mathrm{CFE}$ as it has been described previously [41]. The assay was performed in a 96-well plate at $30^{\circ} \mathrm{C}$. The total volume of the assay was $200 \mu \mathrm{L}$. The consumption of NADH was measured spectrophotometrically at $340 \mathrm{~nm}$ using a plate reader (Bioteck Instruments $\mathrm{GmbH}$, Luzern, Switzerland). One unit is defined as $1 \mu$ mole of consumed NADH $\mathrm{min}^{-1}$.

Xylulokinase (EC 2.7.1.17) was assayed as described previously [42]. The assay mixture contained $0.2 \mathrm{mM}$ NADH, $50 \mathrm{mM}$ Tris-HCl (pH 7.5), $2 \mathrm{mM} \mathrm{MgCl}_{2}, 2 \mathrm{mM}$ ATP, $0.2 \mathrm{mM}$ phosphoenolpyruvate, $8.5 \mathrm{mM}$ ATP, $2.5 \mathrm{U}$ pyruvate kinase, $2.5 \mathrm{U}$ lactate dehydrogenase and $30 \mu \mathrm{L}$ CFE. The assay was performed at $30^{\circ} \mathrm{C}$. The total volume was $200 \mu \mathrm{L}$ in each well of the 96-well plate. The consumption of NADH was measured spectrophotometrically at $340 \mathrm{~nm}$ (Bioteck Instruments $\mathrm{GmbH}$, Luzern, Switzerland). One unit is defined as $1 \mu$ mole of consumed NADH $\min ^{-1}$.

\section{Analytical methods \\ Cell growth}

Growth of bacterial cells was followed by measuring the optical density at $600 \mathrm{~nm}\left(\mathrm{OD}_{600}\right)$ using a UV-visible spectrophotometer (Genesys 6, ThermoSpectronic, Lausanne, Switzerland).

Cell dry weight (CDW) was determined using pre-weighed polycarbonate filters (pore size: $0.2 \mu \mathrm{m}$, Whatman, Scheicher \& Schuell, Dassel, Germany). An appropriate volume $(0.5$ to $5 \mathrm{~mL})$ of culture was filtered in order to obtain a biomass weight of about $2 \mathrm{mg}$ per filter. The filter was dried overnight at $105^{\circ} \mathrm{C}$, cooled down to room temperature in a desiccator and then weighted. The weight difference was used to determine the quantity of biomass per culture volume.

The optical density was correlated to cell dry weight with a ratio of $\mathrm{CDW} / \mathrm{OD}=0.6$ when the cells did not contain PHA and with a ratio of $\mathrm{CDW} / \mathrm{OD}=0.5$ when the cells contained PHA.

The maximum specific growth rate was calculated by the $\log$ of the biomass concentration (expressed in OD in this study) at time $t_{2}$ minus the $\log$ of the biomass concentration at time $t_{1}$ divided by the time interval during the exponential growth phase.

$$
\mu=\frac{\ln X_{2}-\ln X_{1}}{t_{2}-t_{1}}
$$

$\mathrm{X}=$ biomass concentration expressed in $\mathrm{OD}$ values

\section{Measurement of carbon sources}

The consumption of carbon sources was measured by HPLC-MS. Samples were diluted to 0.01 to $0.1 \mathrm{mM}$ with $50 \%$ acetic acid and 50\% acetonitrile $\left(\mathrm{v} \mathrm{v}^{-1}\right)$ and loaded on a reversed phase C18 column (Gemini C18 5 micron, $250 \mathrm{~mm} \times 4.60 \mathrm{~mm}$, Phenomenex, U.K.). A gradient of $100 \%$ diluted formic acid $(0.1 \mathrm{v} \%$ in water) to $100 \%$ acetonitrile was applied as the mobile phase. The flow rate was $0.8 \mathrm{~mL} \mathrm{~min}{ }^{-1}$ and the gradient was completed after $25 \mathrm{~min}$. The peaks were detected by electrospray ionization (ESI) in negative mode [43]. The standard curves for xylose and octanoic acid were recorded in the range of 0.01 to $1 \mathrm{~g} \mathrm{~L}^{-1}$, and $0.005 \mathrm{~g} \mathrm{~L}^{-1}$ to $0.03 \mathrm{~g} \mathrm{~L}^{-1}$, respectively.

\section{Ammonium concentration}

$\mathrm{NH}_{4}^{+}$-nitrogen consumption was detected using an ammonium test kit following the manufacturer instruction (Merck KGaA, 64271 Darmstadt, Germany). The detection limit was $0.01 \mathrm{NH}_{4}^{+}-\mathrm{N}$ mg L${ }^{-1}$. The method was linear up to $3.0 \mathrm{mg} \mathrm{N} \mathrm{L}^{-1}$, above which dilution with distilled water was needed.

\section{Acetic acid measurement}

A DX-500 ion chromatography system (Dionex, Sunnyvale, CA, USA) was used to analyze the acetic acid production during the co-feeding experiments. IonPac AS $11 \mathrm{HC}$ $(250 \mathrm{~mm} \times 4 \mathrm{~mm})$ and AG $11 \mathrm{HC}$ guard $(50 \mathrm{~mm} \times 4 \mathrm{~mm})$ columns were used. Sodium hydroxide gradient of 0.5 to $30 \mathrm{mM}$ allowed the identification and the quantification of this organic acid in $15 \mathrm{~min}$.

\section{PHA content}

For analysis of intracellular PHA the culture broth was centrifuged $\left(10,000 \times \mathrm{g} ; 4^{\circ} \mathrm{C} ; 15 \mathrm{~min}\right)$ and the cell pellet was lyophilized for $48 \mathrm{~h}$. Pyrex vials were weighed to determine the exact transferred biomass, then $2 \mathrm{~mL}$ of 
$15 \% \mathrm{v} \mathrm{v}^{-1} \mathrm{H}_{2} \mathrm{SO}_{4}$ in methanol were added. Furthermore, $2 \mathrm{~mL}$ of methylene chloride containing 2-ethyl-2-hydroxybutyrate $\left(10 \mathrm{~g} \mathrm{~L}^{-1}\right)$ were added as internal standard. The suspension was boiled at $100^{\circ} \mathrm{C}$ for $2.5 \mathrm{~h}$ in an oven. The samples were cooled on ice; then $1 \mathrm{~mL}$ of distilled water was added in order to extract the cell debris that is soluble in the aqueous phase. The sample was mixed by vortexing for $1 \mathrm{~min}$. The complete water phase was discarded (upper phase), including droplets hanging on the tube wall and including the top layer of the chloroform phase. $\mathrm{Na}_{2} \mathrm{SO}_{4}$ powder was added to dry the methylene chloride phase. Two hundred $\mu \mathrm{L}$ of the chloroform phase was filtered using solvent resistant filters (PTFE, $0.45 \mu \mathrm{m}$ ) and transferred to a GC sample tube. PHA content and monomer composition were subsequently analyzed on a GC (A200s, Trace GC 2000 series, Fisons Instruments, Rodano, Italy) equipped with a polar fused silica capillary column (Supelcowax-10: length $30 \mathrm{~m}$; inside diameter $0.31 \mathrm{~mm}$; film thickness $0.5 \mu \mathrm{m}$; Supelco, Buchs, Switzerland). Helium was used as carrier gaz $\left(3 \mathrm{~mL} \mathrm{~min}^{-1}\right)$ and detection was performed with a flame ionization detector (FID) at $285^{\circ} \mathrm{C}$. The temperature was increased from $10^{\circ} \mathrm{C}$ to $280^{\circ} \mathrm{C}$ at a rate of $10^{\circ} \mathrm{C} \mathrm{min}^{-1}$.

Reproducibility All measurements for growth and PHA assays were performed at least in duplicates. The measurements for XylAB assays were performed in triplicates. The data presented in this report are the average numbers.

\section{Competing interests}

The authors declare that they have no competing interests.

\section{Authors' contributions}

SLM carried out the experiments, and drafted the manuscript. MZ and TE participated in the design of the study and helped to draft the manuscript. LTM helped with manuscript preparation. QR conceived of the study, and participated in its design and coordination and helped to draft the manuscript. All authors read and approved the final manuscript.

\section{Acknowledgements}

This study was supported by a grant from the Indo Swiss Joint Research Programme (ISJRP) 123061. We thank Dr. Stéphanie Follonier for her helpful comments.

\section{Author details}

'Laboratory for Biomaterials, Swiss Federal Laboratories for Materials Science and Technology (Empa), Lerchenfeldstrasse 5, St. Gallen CH-9014, Switzerland. ${ }^{2}$ Biotechnology, HES-SO Valais Wallis, Rue du Rawyl 64, P.O.B. 2134, Sion CH-1950, Switzerland. ${ }^{3}$ Environmental Microbiology, Swiss Federal Institute of Aquatic Science and Technology (Eawag), Überlandstrasse 133, P.O. Box 610, Dübendorf CH-8600, Switzerland.

Received: 28 June 2012 Accepted: 17 August 2012

Published: 22 August 2012

\section{References}

1. Anderson AJ, Dawes EA: Occurrence, metabolism, metabolic role and industrial uses of bacterial polyhydroxyalkanoates. Microbiol Rev 1990, 54(4):450-472
2. Senior PJ, Beech GA, Ritchie GAF, Dawes EA: Role of oxygen limitation in formation of poly-beta-hydroxybutyrate during batch and continuous culture of Azotobacter beijerinckii. Biochem J 1972, 128(5):1193-1201.

3. Chen GQ: A microbial polyhydroxyalkanoates (PHA) based bio- and materials industry. Chem Soc Rev 2009, 38(8):2434-2446.

4. Steinbuchel A, Valentin HE: Diversity of bacterial polyhydroxyalkanoic acids. FEMS Microbiol Lett 1995, 128(3):219-228.

5. Madison LL, Huisman GW: Metabolic engineering of poly (3-hydroxyalkanoates): From DNA to plastic. Microbiol Mol Biol Rev 1999, 63(1):21-53.

6. Lokesh BE, Hamid ZAA, Arai T, Kosugi A, Murata Y, Hashim R, Sulaiman O, Mori $Y$, Sudesh K: Potential of oil palm trunk sap as a novel inexpensive renewable carbon feedstock for polyhydroxyalkanoate biosynthesis and as a bacterial growth medium. Clean - Soil, Air, Water 2012, 40(3):310-317.

7. Lee W-H, Loo C-Y, Nomura CT, Sudesh K: Biosynthesis of polyhydroxyalkanoate copolymers from mixtures of plant oils and 3-hydroxyvalerate precursors. Bioresource Technol 2008, 99(15):6844-6851.

8. Lee JH, Hong J, Lim HC: Experimental optimization of fed-batch culture for poly-beta-hydroxybutyric acid production. Biotechnol Bioeng 1997, 56(6):697-705.

9. Solaiman DKY, Ashby RD, Foglia TA, Marmer WN: Conversion of agricultural feedstock and coproducts into poly(hydroxyalkanoates). Appl Microbiol Biotechnol 2006, 71(6):783-789.

10. Solaiman DKY, Swingle BM: Isolation of novel Pseudomonas syringae promoters and functional characterization in polyhydroxyalkanoateproducing pseudomonads. New Biotechnol 2010, 27(1):1-9.

11. Sun ZY, Ramsay JA, Guay M, Ramsay BA: Fermentation process development for the production of medium-chain-length poly-3hydroxyalkanoates. Appl Microbiol Biotechnol 2007, 75(3):475-485.

12. Choi Jl, Lee SY: Process analysis and economic evaluation for poly(3-hydroxybutyrate) production by fermentation. Bioprocess Eng 1997, 17(6):335-342.

13. Beall DS, Ohta K, Ingram LO: Parametric studies of ethanol-production from xylose and other sugars by recombinant Escherichia coli. Biotechnol Bioeng 1991, 38(3):296-303.

14. Sun Y, Cheng JY: Hydrolysis of lignocellulosic materials for ethanol production: a review. Bioresource Techno/ 2002, 83(1):1-11.

15. Xu F, Sun JX, Liu CF, Sun RC: Comparative study of alkali- and acidic organic solvent-soluble hemicellulosic polysaccharides from sugarcane bagasse. Carbohyd Res 2006, 341(2):253-261.

16. Meyer PS, Dupreez JC, Wingfield BD, Kilian SG: Evaluation of Candida blankii hybrids for biomass production. J Biotechnol 1993, 29(3):267-275.

17. Bertrand JL, Ramsay BA, Ramsay JA, Chavarie C: Biosynthesis of poly-betahydroxyalkanoates from pentoses by Pseudomonas pseudoflava. Appl Environ Microb 1990, 56(10):3133-3138.

18. Ramsay JA, Hassan MCA, Ramsay BA: Hemicellulose as a potential substrate for production of poly(beta-hydroxyalkanoates). Can J Microbiol 1995, 41:262-266.

19. Young FK, Kastner JR, May SW: Microbial production of poly-betahydroxybutyric acid from D-xylose and lactose by Pseudomonas cepacia. Appl Environ Microb 1994, 60(11):4195-4198.

20. Lee SY: Poly(3-hydroxybutyrate) production from xylose by recombinant Escherichia coli. Bioprocess Eng 1998, 18(5):397-399.

21. Witholt B, Kessler B: Perspectives of medium chain length poly (hydroxyalkanoates), a versatile set of bacterial bioplastics. Curr Opin Biotech 1999, 10(3):279-285.

22. Sun ZY, Ramsay JA, Guay M, Ramsay BA: Carbon-limited fed-batch production of medium-chain-length polyhydroxyalkanoates from nonanoic acid by Pseudomonas putida KT2440. Appl Microbiol Biotechnol 2007, 74(1):69-77.

23. Meijnen JP, de Winde JH, Ruijssenaars HJ: Engineering Pseudomonas putida $\mathrm{S} 12$ for efficient utilization of D-xylose and L-arabinose. Appl Environ Microb 2008, 74(16):5031-5037.

24. Hoffmann N, Rehm BHA: Regulation of polyhydroxyalkanoate biosynthesis in Pseudomonas putida and Pseudomonas aeruginosa. FEMS Microbiol Lett 2004, 237(1):1-7.

25. Huijberts GNM, Eggink G, Dewaard P, Huisman GW, Witholt B: Pseudomonas putida KT2442 cultivated on glucose accumulates Poly(3-hydroxyalkanoates) consisting of saturated and unsaturated monomers. Appl Environ Microb 1992, 58(2):536-544. 
26. Timm A, Steinbuchel A: Formation of polyesters consisting of medium-chain-length 3-hydroxyalkanoic acids from gluconate by Pseudomonas aeruginosa and other fluorescent Pseudomonads. Appl Environ Microb 1990, 56(11):3360-3367.

27. Fuhrer $T$, Fischer $E$, Sauer U: Experimental identification and quantification of glucose metabolism in seven bacterial species. J Bacterio/ 2005 187(5):1581-1590.

28. Ren Q, de Roo G, Ruth K, Witholt B, Zinn M, Thony-Meyer L: Simultaneous accumulation and degradation of polyhydroxyalkanoates: Futile cycle or clever regulation? Biomacromolecules 2009, 10(4):916-922.

29. Meijnen JP, de Winde $\mathrm{JH}$, Ruijssenaars HJ: Establishment of oxidative D-xylose metabolism in Pseudomonas putida S12. Appl Environ Microb 2009, 75(9):2784-2791.

30. Song SG, Park C: Utilization of D-ribose through D-xylose transporter. FEMS Microbiol Lett 1998, 163(2):255-261.

31. Saier MH: Bacterial phosphoenolpyruvate: Sugar phosphotransferase systems: Structural, functional, and evolutionary interrelationships. Bacteriol Rev 1977, 41(4):856-871.

32. Sawyer MH, Baumann P, Baumann L, Berman SM, Canovas JL, Berman RH: Pathways of D-fructose catabolism in species of Pseudomonas. Arch Microbiol 1977, 112(1):49-55.

33. Follonier S, Panke S, Zinn M: A reduction in growth rate of Pseudomonas putida KT2442 counteracts productivity advances in medium-chainlength polyhydroxyalkanoate production from gluconate. Microb Cell Fact 2011, 10:25.

34. Koller M, Atlić A, Dias M, Reiterer A, Braunegg G: Microbial PHA production from waste raw materials. In Plastics from Bacteria. 14th edition. Edited by Chen GG-Q. Heidelberg: Springer Berlin; 2010:85-119.

35. Sun Z, Ramsay JA, Guay M, Ramsay B: Increasing the yield of MCL-PHA from nonanoic acid by co-feeding glucose during the PHA accumulation stage in two-stage fed-batch fermentations of Pseudomonas putida KT2440. J Biotechnol 2007, 132(3):280-282.

36. Sun ZY, Ramsay J, Guay M, Ramsay B: Enhanced yield of medium-chainlength polyhydroxyalkanoates from nonanoic acid by co-feeding glucose in carbon-limited, fed-batch culture. J Biotechno/ 2009, 143(4):262-267.

37. Kim GJ, Lee IY, Yoon SC, Shin YC, Park YH: Enhanced yield and a high production of medium-chain-length poly(3-hydroxyalkanoates) in a twostep fed-batch cultivation of Pseudomonas putida by combined use of glucose and octanoate. Enzyme Microb Tech 1997, 20(7):500-505.

38. Kessler B, Delorenzo $V$, Timmis KN: A general system to integrate LacZ fusions into the chromosomes of gram-negative Eubacteria - Regulation of the $\mathrm{Pm}$ promoter of the Tol plasmid studied with all controlling elements in monocopy. Mol Gen Genet 1992, 233(1-2):293-301.

39. Delorenzo V, Eltis L, Kessler B, Timmis KN: Analysis of Pseudomonas gene-products using lacl ${ }^{9} /$ Ptrp-lac plasmids and transposons that confer conditional phenotypes. Gene 1993, 123(1):17-24.

40. Maniatis T, Fritsch EF, Sambrook J (Eds): Molecular cloning: a laboratory manual. New York: Cold Spring Harbor edn; 1982.

41. Callens M, Kerstershilderson H, Vanopstal O, Debruyne CK: Catalytic properties of D-xylose isomerase from Streptomyces violaceoruber. Enzyme Microb Tech 1986, 8(11):696-700.

42. Eliasson A, Boles E, Johansson B, Osterberg M, Thevelein JM, SpencerMartins I, Juhnke H, Hahn-Hagerdal B: Xylulose fermentation by mutant and wild-type strains of Zygosaccharomyces and Saccharomyces cerevisiae. Appl Microbiol Biotechnol 2000, 53(4):376-382.

43. Ren Q, Grubelnik A, Hoerler M, Ruth K, Hartmann R, Felber H, Zinn M: Bacterial poly(hydroxyalkanoates) as a source of chiral hydroxyalkanoic acids. Biomacromolecules 2005, 6(4):2290-2298.

doi:10.1186/1472-6750-12-53

Cite this article as: Le Meur et al:: Production of medium-chain-length polyhydroxyalkanoates by sequential feeding of xylose and octanoic acid in engineered Pseudomonas putida KT2440. BMC Biotechnology 2012 12:53.

\section{Submit your next manuscript to BioMed Central and take full advantage of:}

- Convenient online submission

- Thorough peer review

- No space constraints or color figure charges

- Immediate publication on acceptance

- Inclusion in PubMed, CAS, Scopus and Google Scholar

- Research which is freely available for redistribution

Submit your manuscript at www.biomedcentral.com/submit
C BioMed Central 